\title{
Caricaturas da Revista Ilustrada
}

Caricatures of Revista Ilustrada

Caricaturas de la Revista Ilustrada

Cézar de Alencar Arnaut de Toledo Universidade Estadual de Maringá (Brasil)

https://orcid.org/0000-0002-7813-7950

http://lattes.cnpq.br/2085468611285004 caatoledo@uem.com

Fabrícia de Cássia Grou de Paula Universidade Estadual de Maringá (Brasil) https://orcid.org/0000-0002-8348-0470 http://lattes.cnpq.br/2204040490009488 fabigrou@hotmail.com

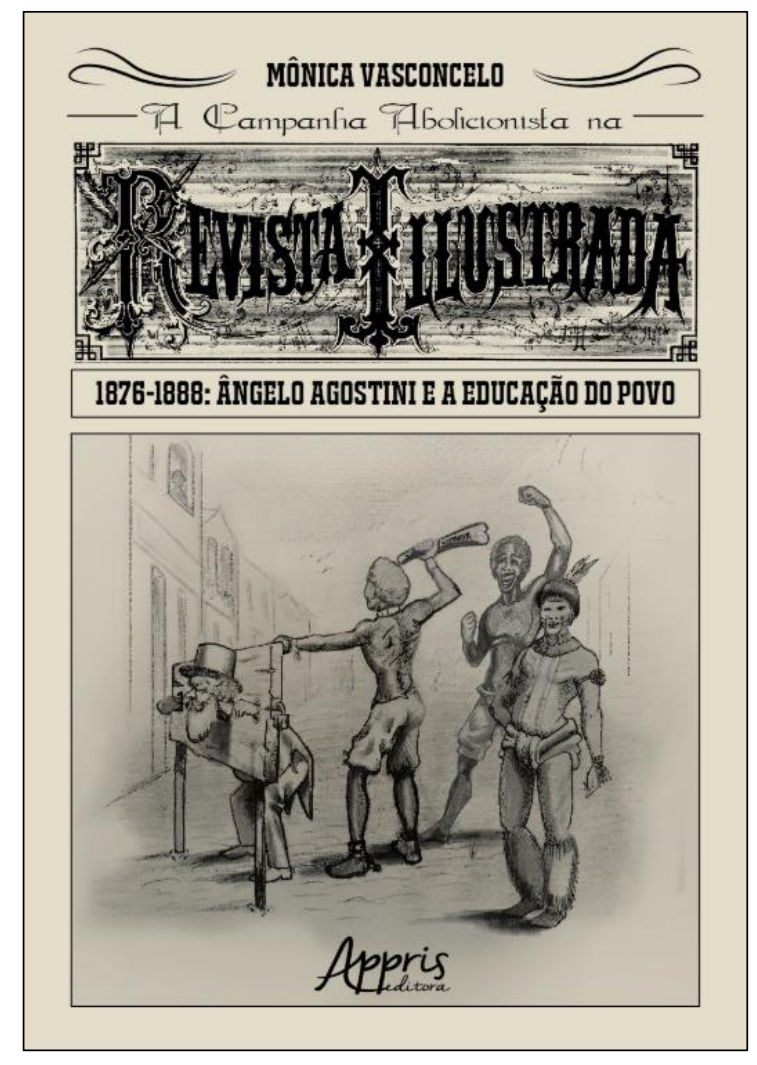

VASCONCELO, Mônica. A Campanha Abolicionista na Revista Ilustrada (1876-1888): Ângelo Agostini e a educação do povo. Curitiba: Appris, 2018. 
A obra é resultado da dissertação de mestrado defendida em 2017 no Programa de Pósgraduação em Educação da Universidade Estadual de Maringá. No livro, Mônica Vasconcelo analisa as caricaturas de Ângelo Agostini (1843-1910) publicadas na Revista Illustrada (18761888), na província do Rio de Janeiro, com a temática da defesa do fim da escravidão. $\mathrm{O}$ objetivo dessa obra é compreender a totalidade social e histórica bem como as contradições presentes no discurso da escravidão. A ação política e educativa inerente ao próprio discurso e aos interesses da classe dominante sombreava a participação de Ângelo Agostini nos embates sobre a abolição do regime escravocrata.

Ângelo Agostini nasceu na província de Alessandria, na Itália, em 1843. Viveu sua infância e adolescência em Paris, onde aprendeu a arte do desenho litográfico. Em 1859, Agostini chega ao Brasil e, anos mais tarde, insere-se no debate político abolicionista. Fundou a Revista Illustrada em 1876 com o ideal de que o periódico servisse como uma publicação política, abolicionista e republicana, temas tratados de forma satírica e irônica.

A apresentação do livro é feita pela própria autora, sucedida pelo prefácio escrito por Marcília Rosa Periotto, professora aposentada do Departamento de Fundamentos da Educação da Universidade Estadual de Maringá. A obra é dividida e três capítulos centrados na questão da imprensa e escravidão a partir das caricaturas feitas por Agostini para a Revista Illustrada.

No primeiro capítulo, intitulado "A Revista Illustrada: caracterização e fundadores" (p. 17-50), a autora faz um breve histórico sobre a imprensa no Brasil do século XIX, com destaque da importante influência da Família Real Portuguesa, responsável por trazer ao país a primeira máquina de impressão. Desde então, a imprensa ganha destaque com o surgimento de outras revistas ilustradas, utilizadas como veículo para a propagação de ideias dos grupos em luta pelo poder político e econômico, bem como as ideias referentes às causas da abolição. A principal crítica da revista faz menção aos problemas encontrados na sociedade do Rio de Janeiro. No ano de 1876, Agostini fundou a Revista Illustrada, com a publicação política abolicionista republicana, as páginas eram compostas pelas caricaturas que marcavam o posicionamento do jornalista em prol do fim do regime escravista. A estratégia de proporcionar interatividade entre o autor e o leitor era um meio utilizado pela Revista com o fim de ampliar seu público. A seção, bem organizada, era um espaço literário de referência e incentivo à leitura, com acesso e informações sobre o autor da obra, o assunto, sua relevância e localização.

No segundo capitulo, "A ambiência política no Brasil do século XIX” (p. 51-85), Vasconcelo explica as relações do contexto social e político do Brasil ao longo do século XIX, assim como os debates sobre o fim da escravidão que, naquele momento, era considerado a 
atividade fundante da produção da riqueza nacional. A apresentação do contexto histórico da época, permite compreender a cisão entre conservadores e liberais que apresentavam em seus respectivos discursos a defesa pela manutenção ou pela abolição das questões relacionadas à escravidão. O partido Conservador originava-se de uma coalizão de burocratas proprietários de terras, enquanto o Partido Liberal vinha de uma coalizão de profissionais liberais e donos de terra. No século XIX ambos os partidos se aproveitaram de fraudes eleitorais e manobras políticas para manter-se no poder, os Liberais, por sua vez pregavam o fortalecimento do parlamento defendiam a descentralização do poder imperial, isto é, autonomia das províncias. Apesar de ambos os partidos serem simpáticos a manutenção do regime escravista, os liberais eram mais contrários ao trabalho escravo, distinguindo-se por entenderem que sua supressão deveria ser conduzida por um processo gradual que levaria a abolição definitiva. Nesse contexto, conforme destacado pela autora, a imprensa atuou como articuladora dos debates, acompanhando todo o processo de escravatura e abolição. Após 1880 o número de jornais abolicionista aumentou, mas eram minoria se comparados aos periódicos defensores da escravidão e indiferente a causa. Os jornais que combatiam a escravidão, apareciam como um projeto de modernidade para o Brasil.

O terceiro e último capítulo, intitulado "O caráter educativo da campanha abolicionista de Ângelo Agostini na Revista Illustrada (1876-1888)" (p. 87-124) expõe o caráter educativo da campanha abolicionista de Ângelo Agostini no referido periódico. Os desenhos caricaturais ultrapassavam as dificuldades existentes na utilização da linguagem escrita, levando em conta que a maior parte da população brasileira era analfabeta, a arte visual era uma estratégia de passar as mensagens contidas nas caricaturas. Após a abolição, ocorrida em 1888, os caricaturistas passaram a criticar a falta de assistência aos escravos libertos com mais de 60 anos, e sugeriram que fossem criados asilos para abrigar os desamparados. A autora afirma que a análise das caricaturas permitiu observar que Agostini apresentou uma maneira muito própria de expor suas ideias a respeito do tema defendido. As críticas do caricaturista sobre a forma de ser da sociedade brasileira e de seus autores principais acompanhavam a conjuntura sociopolítica, logo, a revista atuante nas causas abolicionista assumiu o dever de honrar o seu programa:" falar a verdade, e combater os abusos e distribuir justiça". Deste o início apresentouse como um veículo de resistência as pressões escravocratas, agiu de forma didática e contextualizada. A revista com caráter educativo, uma vez que formava opiniões do público leitor por meio das caricaturas publicadas. 
A conclusão chegada pela autora após a análise das caricaturas veiculadas na Revista Illustrada, é que estas auxiliam no entendimento da luta pela abolição, de caráter político e educativo, cuja função era a de instruir a opinião pública. A educação constituiu-se num fenômeno realizado nos mais diversos âmbitos sociais e nesse aspecto, a análise do debate político e das caricaturas em torno do tema da escravidão permite compreender os processos de luta e de formação das ideias da sociedade do século XXI, as quais até os dias de hoje ainda perduram no movimento histórico-social.

As caricaturas de Agostini expressam a inquietação e incompatibilidade das ideias do caricaturista com aquele arranjo social, como destaca a autora há nelas uma sintomática militância, oriunda de um entendimento que considerava os processos sociais continuamente mobilizados pelo fazer humano, por tanto sempre em transformação.

Na certeza do caráter pedagógico desempenhado pela imprensa, Ângelo Agostini, por intermédio de suas caricaturas publicadas pela Revista Illustrada, atuou como formador da opinião pública, visto que seus desenhos denunciavam a urgência da transformação de um sistema de trabalho que já não encontrava nas bases do tecido social, a sustentação necessária para sua manutenção. À época, urgia a transposição do escravismo, contrário à civilidade humana, pelo trabalho livre, condizente com o ideal de progresso e de modernidade.

A obra ora apresentada constitui uma importante contribuição para a área da educação e da história da imprensa no Brasil. A autora apresenta uma análise consistente e bem documentada, alicerçada em um amplo e respeitado referencial teórico. 